\title{
Genetic diversity of the North African catfish, Clarias gariepinus (Burchell, 1822) hatchery stocks in Thailand
}

\author{
Anyalak Wachirachaikarn ${ }^{\mathrm{a}, \mathrm{b}}$, Uthairat Na-Nakorn ${ }^{\mathrm{c}, *}$ \\ a Division of Genetics, Department of Sciences, Faculty of Liberal Arts and Science, Kasetsart University, \\ Kamphaeng Saen Campus, Nakhon Pathom 73140 Thailand \\ b Research Unit of Genetic Technology and Applications, Department of Science, Faculty of Liberal Arts \\ and Science, Kasetsart University, Kamphaeng Saen Campus, Nakhon Pathom 73140 Thailand \\ c Department of Aquaculture, Faculty of Fisheries, Kasetsart University, Bangkok 10900 Thailand
}

*Corresponding author, e-mail: ffisurn@ku.ac.th

Received 21 May 2018

Accepted 6 Jun 2019

\begin{abstract}
Information on levels of genetic variation is a prerequisite for successful natural resource management and genetic improvement programs. In this study we aimed to identify genetically distinct stocks of North African catfish, Clarias gariepinus (Burchell, 1822) in Thailand which could be used as germplasm sources for a selective breeding program. Four hatchery stocks $(n=50$ fish/population) were sampled, three from northeastern provinces (Sakon Nakhon, SN; Nong Khai, NK; and Nakhon Ratchasima, NR), and one from central Thailand (Nakhon Nayok, NY). Six microsatellite loci were scored using primers developed for this species. The results revealed significant genetic differentiation among stocks $\left(F_{\mathrm{ST}}=0.096 ; \mathrm{CI}=0.045-0.166\right)$ with all but one pair of stocks (NK vs SN) being significantly different, as shown by pair-wise $F_{\mathrm{ST}}$. Three stocks showed homozygote excess. Further analyses showed no recent bottlenecks, but some evidence of genotype disequilibrium. Allele diversity was low ( $A$ ranged from 6.00-7.00; $A_{e}$ ranged from 3.43-4.59) while heterozygosity was moderate ( $H_{o}$ ranged from $0.52-0.72 ; H_{e}$ ranged from $\left.0.67-0.77\right)$. The effective population sizes $\left(N_{e}\right)$ based on linkage disequilibrium method were between 22.2 and 133 individuals. The neighbor-joining (NJ) tree was robust and revealed the closest genetic relationship between SN and NK, which were clearly separated from NR and NY. Two groups of stocks (northeastern, NK+NR+SN vs NY) showed highest variation among groups (13\%) as revealed by AMOVA. The results apparently revealed genetically distinct stocks of North African catfish in Thailand which are useful for establishing a base population for a genetic improvement program.
\end{abstract}

KEYWORDS: African catfish, germplasm, base population, microsatellite

\section{INTRODUCTION}

Aquaculture plays a significant role in producing seafood to fulfill a booming global protein demand. However, while more production is required, available resources for aquaculture, especially land and water, are limited ${ }^{1}$. This situation has led to a favoring of species that can tolerate high stocking densities and poor water quality. Among these is the North African catfish, Clarias gariepinus (Burchell 1822) ( $\mathrm{Cg}$ ), which has been widely adopted for aquaculture within and outside its native ranges 2,3 and with a global production of $231094 \mathrm{mt}$ in $2016^{4}$. Cg has been intensively translocated, mainly within Africa and Asia and, to a lesser extent, to Europe and Latin America ${ }^{3}$. There has been a concern that the introduced stocks, after a few generations in hatcheries, would show a decline of genetic variation, as has been documented for introduced/hatchery stocks of $\mathrm{Cg}^{5-7}$ with a few exceptions ${ }^{8,9}$. This eventually compromised the species' performance in aquaculture.

Thailand is an important producer of Clarias catfish (e.g. $122418 \mathrm{mt}$ in 2016, ranked second after Nigeria ${ }^{4}$ ), and $90 \%$ of the production is comprised of the hybrid between female native bighead catfish, Clarias macrocephalus Günther, 1864 and male $\mathrm{Cg}$ introduced from Vietnam via Laos in $1987^{10}$. However, the culture of $\mathrm{Cg}$ is rapidly expanding due to its superior growth and disease resistance and increasing consumer acceptance. It is believed that more than one stock of $\mathrm{Cg}$ has been introduced to Thailand ${ }^{11}$ although the historical records of the introductions are lacking.

Despite their importance as a potential source of germplasm for genetic improvement, Cg stocks in Thailand have been rarely explored for their 


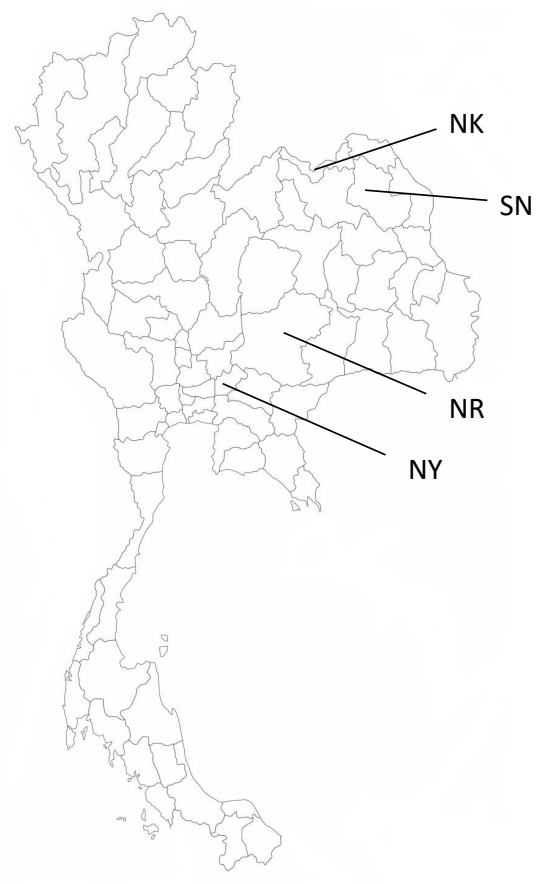

Fig. 1 A map of Thailand showing locations of the North African catfish hatcheries where samples were collected for this study.

genetic diversity. In 2008, four Cg stocks were identified (genetic distance, $d=0.036-0.144$ ) using microsatellite data (6 loci) ${ }^{12}$ and two of them were used in a cross-breeding experiment. Recently, Koolboon et $\mathrm{al}^{13}$, using five microsatellite loci, observed genetic differences among three $\mathrm{Cg}$ stocks $(d=0.031-0.066)$ with significantly different growth performance. Owing to the fact that genetic diversity changes over time due to broodstock management regimes, the present study aimed to verify genetically different $\mathrm{Cg}$ stocks present in Thailand, and to quantify genetic variation within populations. The information obtained is useful for improving broodstock management and genetic improvement programs for which genetically distinct stocks are required.

\section{MATERIALS AND METHODS}

\section{Fish samples and DNA extraction}

Fin-clips were collected from catfish at four commercial hatcheries ( $\mathrm{n}=50$ fish/hatchery) in Thailand located in three northeastern provinces, Sakon Nakhon (SN), Nong Khai (NK), and Nakhon Ratchasima (NR), and a central province, Nakhon Nayok (NY) (Fig. 1). These hatcheries were selected according to history of the stock ( $>5$ generations of rearing at each farm, and had potentially originated from different founder stocks). The samples were individually preserved in $95 \%$ ethanol until use. DNA was extracted using the standard phenolchloroform protocol modified from Taggart et $\mathrm{al}^{14}$ and preserved in TE buffer ( $10 \mathrm{mM}$ Tris- $\mathrm{HCl} \mathrm{pH} \mathrm{7.6,}$ $1 \mathrm{mM}$ EDTA pH 8.0) at $4^{\circ} \mathrm{C}$ until use. All of the protocols were approved by the Kasetsart University Animal Ethics Committee (ID ACKU 61-FIS-004).

\section{Microsatellite primers and PCR profile}

Six microsatellite primers, Cga01, Cga02, Cga03, Cga06, Cga09, and Cga10, developed by Galbusera et $\mathrm{al}^{15}$ (Table 1) were used. Each $10 \mu \mathrm{l}$ of PCR reactions comprised $10 \mathrm{ng}$ DNA template, 0.25 pmol each of forward and reverse primer, 1X PCR buffer, $1.5 \mathrm{mM} \mathrm{MgCl}_{2}, 100 \mu \mathrm{M} \mathrm{dNTPs}$, and 0.2 unit Taq DNA polymerase (Fermentas). The PCR profile (PTC-100TM Programmable Thermal Controller; MJ Research, Inc.) was as follows: 5 min initial denaturation at $95^{\circ} \mathrm{C}$; 35 cycles of $30 \mathrm{sec}$ of denaturation at $95^{\circ} \mathrm{C} ; 30 \mathrm{sec}$ at annealing temperature $\left(52-56^{\circ} \mathrm{C}\right)^{15}$; and $1 \mathrm{~min}$ of extension at $72^{\circ} \mathrm{C}$, and $5 \mathrm{~min}$ at $72^{\circ} \mathrm{C}$. The PCR products were then electrophoresed onto $4.5-6 \%$ denaturing polyacrylamide gel and visualized by silver staining. M13 ladder was used as size marker. To minimize scoring errors within and across gels, the marker was loaded into the first, middle and last lanes, and two PCR products of known allele size were included for all gels.

\section{Statistical analyses}

The individual multilocus genotypes were used for the following statistical analyses. Firstly, each population was tested for Hardy-Weinberg Equilibrium (HWE) and genotypic disequilibrium using exact $p$ value Markov chain ${ }^{16}$, facilitated by the computer package GENEPOP V3.4 ${ }^{17}$, and adjusted multiple test with Bonferroni correction ${ }^{18,19}$. Then the populations showing homozygote excess were tested for the presence of null alleles (alleles that were not amplified), and the genotypic data were adjusted according to the suggestion from the MICROCHECKER program ${ }^{20}$. Then the populations were tested against HWE again. Subsequently, the genetic variation within populations, allele frequency, average number of alleles per locus $(A)$, average effective number of alleles per locus $\left(A_{e}\right)$, and observed and expected heterozygosity per individual $\left(H_{o}\right.$ and $H_{e}$, respectively) were calculated using the GENEPOP 
Table 1 Detail of six microsatellite loci developed for North African catfish by Galbusera et al $^{15}$ and allele size ranges found in four populations used in this study.

\begin{tabular}{|c|c|c|c|c|c|}
\hline Locus & GenBank & Motif & Primer sequence $5^{\prime}-3^{\prime}$ & $\mathrm{T}_{\mathrm{A}}^{\dagger}\left({ }^{\circ} \mathrm{C}\right)$ & Size (bp) \\
\hline Cga01 & U30862 & $(\mathrm{GT})_{15}$ & $\begin{array}{l}\text { GGCTAAAAGAACCCTGTCTG } \\
\text { TACAGCGTCGATAAGCCAGG }\end{array}$ & 52 & $85-201$ \\
\hline Cga02 & U30863 & $(\mathrm{GT})_{10} \mathrm{~N}_{2}(\mathrm{GT})_{8}$ & $\begin{array}{l}\text { GCTAGTGTGAACGCAAGGC } \\
\text { ACCTCTGAGATAAAACACAGC }\end{array}$ & 54 & $96-118$ \\
\hline Cga03 & U30864 & $(\mathrm{GT})_{21}$ & $\begin{array}{l}\text { CACTTCTTACATTTGTGCCC } \\
\text { ACCTGTATTGATTTCTTGCC }\end{array}$ & 56 & $136-176$ \\
\hline Cga06 & U30867 & $(\mathrm{GT})_{5} \mathrm{~N}_{2}(\mathrm{GT})_{9}$ & $\begin{array}{l}\text { CAGCTCGTGTTTAATTTGGC } \\
\text { TTGTACGAGAACCGTGCCAGG }\end{array}$ & 54 & $134-152$ \\
\hline Cga09 & U30871 & $\begin{array}{l}(\mathrm{GA})_{3} \mathrm{~N}_{3}(\mathrm{GT})_{11} \\
\mathrm{~N}(\mathrm{GT})_{6} \mathrm{~N}_{2}(\mathrm{GT})_{4}\end{array}$ & $\begin{array}{l}\text { CGTCCACTTCCCCTAGAGCG } \\
\text { CCAGCTGCATTACCATACATGG }\end{array}$ & 56 & 174-192 \\
\hline Cga10 & U30870 & $(\mathrm{GT})_{2} \mathrm{~N}_{2}(\mathrm{GT})_{15}$ & $\begin{array}{l}\text { GCTGTAGCAAAAATGCAGATGC } \\
\text { TCTCCAGAGATCTAGGCTGTCC }\end{array}$ & 54 & $107-117$ \\
\hline
\end{tabular}

$\dagger \mathrm{T}_{\mathrm{A}}=$ annealing temperature.

V3.4 ${ }^{17}$. Effective population size $\left(N_{e}\right)$ of each population was estimated based on linkage disequilibrium using the program NeEstimator (V2) ${ }^{21}$.

Genetic diversity between populations was assessed as follows. $F$-coefficient was calculated using the computer package FSTAT ${ }^{22}$ to test if the studied populations were genetically different. Then pairwise population differentiation was tested using ARLEQUIN V3.0123. Cavalli-Sforza and Edwards genetic distance was calculated using the software PHYLIP V3.63 ${ }^{24}$. Then the genetic distance ${ }^{25}$ was used to reconstruct a neighbor-joining tree and bootstrapping using the same software. Bonferroni correction was applied to adjust critical probability for multiple tests.

To clearly distinguish population groups, AMOVA (analysis of molecular variance) was performed between northeastern populations $(\mathrm{SN}+\mathrm{NK}+\mathrm{NR})$ and $\mathrm{NY} ; \mathrm{SN}+\mathrm{NK}$ and $\mathrm{NR}$ and $\mathrm{NY}$; $\mathrm{SN}+\mathrm{NK}$ and NY+NR using ARLEQUIN V3.01 ${ }^{23}$.

\section{RESULTS}

\section{HWE and linkage disequilibrium}

Three stocks (SN, NK, and NY) departed from HWE towards homozygote excess $(p<0.001)$ at three (Cga03, Cga06 and Cga10), two (Cga01 and Cga03), and one loci (Cga10), respectively ( $p<$ 0.0016 , Bonferroni correction) and the test revealed the presence of null alleles at three loci. However, even after the genotypes were adjusted according to the suggestion provided by the program, the tests still showed departure from HWE in these popu- lations. Recent bottleneck test showed normal Lshaped distribution, which implied no evidence for recent inbreeding in these populations. Genotype disequilibrium, non-random segregation of different loci in a gamete, was detected at only three pairs of loci (Cga01-Cga06, Cga01-Cga10, and Cga02Cga03) ( $p<0.00067$ after Bonferroni correction), with the highest incidence in NY (3 loci pairs) and one each in SN and NK. No genotype disequilibrium was detected for NR.

\section{Genetic variation within populations}

Among the populations studied, NY possessed the largest number of private alleles (2 alleles of Cga01, 5 alleles of Cga03, 3 alleles of Cga09, and 1 allele at Cga10) while NR and NK had only three (1 allele of Cga01 and 2 alleles of Cga06), and one private allele (of Cga06), respectively (Table 2). Genetic variation within the four populations was characterized by low average number of alleles per locus and average effective number of alleles per locus ( $A$ weighted with allele frequencies). Heterozygosity (observed and expected) was moderate for SN and NK, and high in NR and NY (Table 3). It was noteworthy that no statistical differences were observed among populations for each parameter $(p>0.05)$. The overall $A$ and $A_{e}$ across populations were slightly higher $\left(A=9.5 ; A_{e}=5.08\right)$ than those of individual stocks.

\section{Effective population size $\left(N_{e}\right)$}

$N_{e}$ (lowest allele frequency $=0$ ) based on linkage disequilibrium (LD) was lowest for $\mathrm{NY}\left(N_{e}=22.2\right.$; 
Table 2 Allele frequency distribution of six microsatellite loci in each population of North African catfish in Thailand.

\begin{tabular}{|c|c|c|c|c|c|c|c|c|c|c|c|c|c|}
\hline Locus & Size & SN & NK & NR & NY & $\mathrm{PA}^{\dagger}$ & Locus & Size & SN & NK & NR & $\mathrm{NY}$ & $\mathrm{PA}^{\dagger}$ \\
\hline \multirow[t]{18}{*}{ Cga01 } & $(\mathrm{N})$ & (50) & (50) & (49) & (50) & \multirow{9}{*}{ NY } & \multirow[t]{9}{*}{ Cga06 } & $(\mathrm{N})$ & (49) & (50) & (49) & (50) & \\
\hline & 85 & 0.02 & 0.01 & 0.00 & 0.00 & & & 134 & 0.00 & 0.00 & 0.10 & 0.00 & NR \\
\hline & 87 & 0.10 & 0.12 & 0.19 & 0.02 & & & 136 & 0.27 & 0.45 & 0.29 & 0.20 & \\
\hline & 95 & 0.00 & 0.08 & 0.20 & 0.17 & & & 138 & 0.28 & 0.12 & 0.32 & 0.14 & \\
\hline & 97 & 0.31 & 0.23 & 0.00 & 0.00 & & & 140 & 0.28 & 0.16 & 0.08 & 0.25 & \\
\hline & 101 & 0.13 & 0.09 & 0.06 & 0.02 & & & 142 & 0.18 & 0.22 & 0.11 & 0.35 & \\
\hline & 103 & 0.13 & 0.07 & 0.05 & 0.11 & & & 148 & 0.00 & 0.00 & 0.01 & 0.00 & NR \\
\hline & 109 & 0.00 & 0.00 & 0.00 & 0.01 & & & 150 & 0.00 & 0.01 & 0.09 & 0.06 & \\
\hline & 111 & 0.06 & 0.05 & 0.18 & 0.25 & & & 152 & 0.00 & 0.04 & 0.00 & 0.00 & NK \\
\hline & 113 & 0.01 & 0.12 & 0.08 & 0.14 & & \multirow[t]{11}{*}{ Cga09 } & $(\mathrm{N})$ & (50) & (50) & (49) & (50) & \\
\hline & 115 & 0.02 & 0.05 & 0.00 & 0.00 & & & 174 & 0.00 & 0.00 & 0.00 & 0.16 & NY \\
\hline & 119 & 0.00 & 0.00 & 0.03 & 0.08 & & & 176 & 0.00 & 0.00 & 0.00 & 0.02 & NY \\
\hline & 121 & 0.10 & 0.05 & 0.07 & 0.00 & & & 178 & 0.14 & 0.07 & 0.10 & 0.00 & \\
\hline & 127 & 0.00 & 0.00 & 0.00 & 0.01 & NY & & 180 & 0.00 & 0.01 & 0.07 & 0.10 & \\
\hline & 129 & 0.04 & 0.10 & 0.11 & 0.05 & & & 182 & 0.04 & 0.10 & 0.21 & 0.26 & \\
\hline & 133 & 0.03 & 0.03 & 0.00 & 0.06 & & & 184 & 0.17 & 0.20 & 0.17 & 0.19 & \\
\hline & 135 & 0.05 & 0.00 & 0.00 & 0.08 & & & 186 & 0.09 & 0.13 & 0.05 & 0.07 & \\
\hline & 201 & 0.00 & 0.00 & 0.01 & 0.00 & NR & & 188 & 0.05 & 0.05 & 0.02 & 0.00 & \\
\hline \multirow[t]{8}{*}{$\mathrm{Cga02}$} & $(\mathrm{N})$ & (49) & (50) & (48) & (50) & & & 190 & 0.00 & 0.00 & 0.00 & 0.01 & NY \\
\hline & 96 & 0.00 & 0.00 & 0.05 & 0.02 & & & 192 & 0.51 & 0.44 & 0.37 & 0.19 & \\
\hline & 106 & 0.47 & 0.40 & 0.26 & 0.29 & & \multirow[t]{7}{*}{ Cga10 } & $(\mathrm{N})$ & (50) & (50) & (49) & (50) & \\
\hline & 108 & 0.02 & 0.04 & 0.00 & 0.01 & & & 107 & 0.00 & 0.02 & 0.02 & 0.12 & \\
\hline & 110 & 0.13 & 0.19 & 0.12 & 0.33 & & & 109 & 0.02 & 0.06 & 0.09 & 0.16 & \\
\hline & 114 & 0.11 & 0.08 & 0.13 & 0.07 & & & 111 & 0.13 & 0.20 & 0.26 & 0.55 & \\
\hline & 116 & 0.02 & 0.04 & 0.02 & 0.12 & & & 113 & 0.65 & 0.55 & 0.45 & 0.00 & \\
\hline & 118 & 0.25 & 0.25 & 0.43 & 0.16 & & & 115 & 0.00 & 0.00 & 0.00 & 0.01 & NY \\
\hline \multirow[t]{10}{*}{$\mathrm{Cga03}$} & $(\mathrm{N})$ & (49) & (49) & (47) & (50) & & & 117 & 0.20 & 0.17 & 0.18 & 0.16 & \\
\hline & 136 & 0.00 & 0.00 & 0.00 & 0.20 & \multirow{9}{*}{$\begin{array}{l}\mathrm{NY} \\
\mathrm{NY} \\
\mathrm{NY} \\
\mathrm{NY} \\
\mathrm{NY}\end{array}$} & & & & & & & \\
\hline & 138 & 0.00 & 0.00 & 0.00 & 0.14 & & & & & & & & \\
\hline & 140 & 0.00 & 0.00 & 0.00 & 0.23 & & & & & & & & \\
\hline & 142 & 0.00 & 0.00 & 0.00 & 0.36 & & & & & & & & \\
\hline & 150 & 0.00 & 0.00 & 0.00 & 0.07 & & & & & & & & \\
\hline & 152 & 0.22 & 0.18 & 0.23 & 0.00 & & & & & & & & \\
\hline & 154 & 0.07 & 0.05 & 0.10 & 0.00 & & & & & & & & \\
\hline & 156 & 0.67 & 0.76 & 0.61 & 0.00 & & & & & & & & \\
\hline & 176 & 0.03 & 0.01 & 0.06 & 0.00 & & & & & & & & \\
\hline
\end{tabular}

${ }^{\dagger} \mathrm{PA}=$ private allele.

confidence interval, $\mathrm{CI}=15.9-32.0$ ), moderate for SN $\left(N_{e}=73.2 ; \mathrm{CI}=35.9-344.1\right)$ and $\mathrm{NR}\left(N_{e}=\right.$ 71.1; CI = 37.3-241.9), and highest for NK $\left(N_{e}=\right.$ 133.0; CI = 54.7-infinite).

\section{Genetic diversity between populations}

Overall $F_{\mathrm{ST}} \quad(0.096 \pm 0.034)$ was significantly greater than zero (bootstrapping value 0.0450.166 ), and thus revealed significant differences among populations. Pair-wise population differentiation tests showed that all but one population pair (excepted SN vs NK) were significantly different $(p<0.0083$, Bonferroni correction). Likewise, the pair-wise $F_{\mathrm{ST}}$ revealed significant difference between all but one comparison (except for NK and SN).

\section{Genetic distance and a phylogenetic tree}

Genetic distance between populations ranged between 0.025 (NK vs SN) and 0.161 (NY vs SN) (Table 4). Notably, NY showed high genetic distance $(d=0.087-0.161)$ against all other populations. The neighbour-joining tree (Fig. 2) was robust with bootstrap values of $98-100 \%$. The tree confirmed 
Table 3 Genetic variation within populations (locus-wise and average across loci) of four hatchery stocks of North African catfish in Thailand.

\begin{tabular}{lcrrrrr}
\hline Pop/locus & $\mathrm{n}$ & $A$ & $A_{e}$ & $H_{o}$ & $H_{e}$ & \multicolumn{1}{c}{$F_{\text {is }}{ }^{\dagger}$} \\
\hline SN & & & & & & \\
Cga01 & 50 & 12 & 6.27 & 0.80 & 0.85 & 0.058 \\
Cga02 & 49 & 6 & 3.21 & 0.73 & 0.69 & -0.057 \\
Cga03 & 49 & 4 & 1.96 & 0.20 & 0.49 & 0.590 \\
Cga06 & 49 & 4 & 3.91 & 0.41 & 0.75 & 0.460 \\
Cga09 & 50 & 6 & 3.12 & 0.70 & 0.69 & -0.021 \\
Cga10 & 50 & 4 & 2.08 & 0.28 & 0.53 & 0.470 \\
Average & 48.5 & 6.0 & 3.43 & 0.52 & 0.67 & 0.221 \\
\hline NK & & & & & & \\
Cga01 & 50 & 12 & 8.36 & 0.66 & 0.89 & 0.260 \\
Cga02 & 50 & 6 & 3.73 & 0.80 & 0.74 & -0.083 \\
Cga03 & 49 & 4 & 1.65 & 0.10 & 0.40 & 0.745 \\
Cga06 & 50 & 6 & 3.42 & 0.76 & 0.71 & -0.064 \\
Cga09 & 50 & 7 & 3.73 & 0.72 & 0.74 & 0.026 \\
Cga10 & 50 & 5 & 2.66 & 0.52 & 0.63 & 0.177 \\
Average & 50 & 6.7 & 3.93 & 0.59 & 0.69 & 0.135 \\
\hline NR & & & & & & \\
Cga01 & 49 & 10 & 6.91 & 0.75 & 0.86 & 0.127 \\
Cga02 & 48 & 6 & 3.54 & 0.73 & 0.73 & -0.005 \\
Cga03 & 47 & 4 & 2.29 & 0.49 & 0.57 & 0.143 \\
Cga06 & 49 & 7 & 4.55 & 0.86 & 0.79 & -0.089 \\
Cga09 & 49 & 7 & 4.36 & 0.86 & 0.78 & -0.102 \\
Cga10 & 49 & 5 & 3.23 & 0.61 & 0.70 & 0.124 \\
Average & 48.5 & 6.5 & 4.15 & 0.72 & 0.74 & 0.028 \\
\hline NY & & & & & & \\
Cga01 & 50 & 12 & 6.99 & 0.70 & 0.87 & 0.193 \\
Cga02 & 50 & 7 & 4.19 & 0.74 & 0.77 & 0.039 \\
Cga03 & 50 & 5 & 4.05 & 0.72 & 0.76 & 0.054 \\
Cga06 & 50 & 5 & 4.03 & 0.74 & 0.76 & 0.026 \\
Cga09 & 50 & 8 & 5.53 & 0.80 & 0.83 & 0.034 \\
Cga10 & 50 & 5 & 2.72 & 0.50 & 0.64 & 0.218 \\
Average & 50 & 7.0 & 4.59 & 0.70 & 0.77 & 0.092 \\
\hline Overall & 49.8 & 9.5 & 5.08 & 0.63 & 0.77 & 0.116 \\
\hline t No & & & & & & \\
\hline
\end{tabular}

$\dagger$ No statistical difference was observed between populations. $F_{\text {is }}=\left(H_{e}-H_{o}\right) / H_{e}$.

Table 4 Genetic distances (below diagonal) and pairwise $F_{\mathrm{ST}}$ (upper diagonal) among the four hatchery stocks of North African catfish in Thailand based on Carvalli-Sforza and Edwards ${ }^{25}$ genetic distance.

\begin{tabular}{lcccc}
\hline & SN & NK & NR & NY \\
\hline SN & - & 0.010 & $0.043^{* * *}$ & $0.178^{* * *}$ \\
NK & 0.025 & - & $0.029^{* * *}$ & $0.155^{* * *}$ \\
NR & 0.077 & 0.0447 & - & $0.123^{* *}$ \\
NY & 0.161 & 0.118 & 0.087 & - \\
\hline
\end{tabular}

"** denotes highly significant difference $(p<0.001)$.

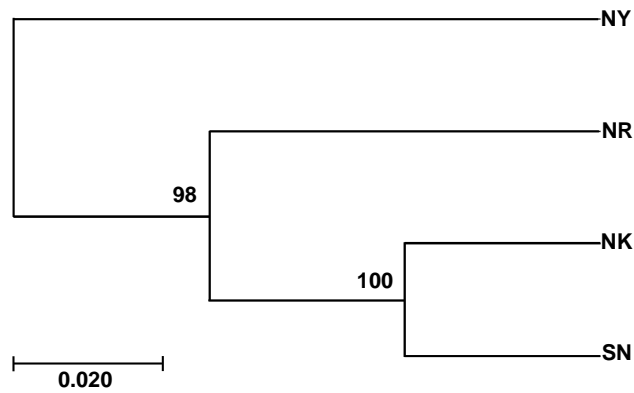

Fig. 2 A neighbor-joining tree of the four hatchery populations of North African catfish in Thailand based on Cavalli-Sforza and Edwards (1967) genetic distance. Bootstrap values are indicated at the nodes.

Table 5 The results of AMOVA between the northeastern stocks (SN, NK and NR) and NY of North African catfish in Thailand.

\begin{tabular}{lrrrr}
\hline $\begin{array}{l}\text { Source of } \\
\text { variation }\end{array}$ & $\begin{array}{l}\text { Sum of } \\
\text { square }\end{array}$ & Variance & \% variation & $p$-value \\
\hline Among groups & 59.09 & 0.342 & 13.45 & .00001 \\
\hline $\begin{array}{l}\text { Among } \\
\text { populations } \\
\text { within group }\end{array}$ & 15.90 & 0.059 & 2.31 & .00001 \\
$\begin{array}{l}\text { Within } \\
\text { populations }\end{array}$ & 840.73 & 2.145 & 84.24 & .00196 \\
\hline Total & 915.72 & 2.546 & & \\
\hline
\end{tabular}

the close genetic relationship between NK and SN, following by NR and NY being the most remote population.

\section{Results of AMOVA analysis}

AMOVA analysis revealed statistically significant variation $(p<0.0001)$ among groups in all three group combinations with variance component among groups ranged from 0.089 ( $\mathrm{SN}+\mathrm{NK}$ and $\mathrm{NR}+\mathrm{NY}$ ) and 0.342 (northeastern and NY). The variance among groups of the latter comprised $13.45 \%$ (Table 5 ) of the variation and was higher than those of the rest $(\sim 10 \%)$. The highest variation occurred within populations (84.24-89.13\%) while the variance among populations within groups comprised only $0.84-7.17 \%$.

\section{DISCUSSION}

\section{Genetic variation of the stocks}

Genetic variation in terms of average number of alleles per locus of hatchery stocks in this study 
fall in the same range as previously reported for four hatchery stocks from central Thailand $(A=$ 4.67-12.17; $\left.A_{e}=3.15-5.80\right)^{12}$, and slightly lower than those of hatchery stocks in Kenya, based on the same sets of microsatellites $(A=8.83-10.83$, $\left.A_{e}=5.5-5.9\right)^{9}$. In general, loss of alleles is commonly occurred in hatchery populations and was accounted by founder effects (using a small number of founders) and subsequent genetic drift and inbreeding ${ }^{26,27}$. However, according to the sufficient estimated $N_{e}$ in most populations reported herein (73-133, except for 22 in NY) the allele loss was unlikely occurred. The minor discrepancy observed herein might be a result of small sample size ( $\mathrm{n}=$ 50) used in the analyses. Noteworthy, $A$ and $A_{e}$ averaged across four stocks were relatively high and thus implied that the allele diversity could be increased by crossing these stocks. Heterozygosities (observed and expected) were moderate to high as compared to the average $H_{o}$ among freshwater fishes $\left(H_{o}=0.54\right)^{28}$, and $H_{o}$ of four $\mathrm{Cg}$ populations from central Thailand $(0.50-0.69)^{12}$.

\section{No evidence of inbreeding}

Although the three stocks showed significant homozygote excess, which may be a sign of inbreeding, the absence of recent bottlenecks indicated that no inbreeding occurred. Rather, the genotype disequilibrium present in these stocks revealed that the homozygote excess could have emerged from the mixing of genetically different populations (Wahlund effect) ${ }^{29}$. Our finding was supported by Wachirachaikarn et $\mathrm{al}^{12}$, wherein both genetic markers and results from the crossing experiment reflected that no inbreeding had occurred in Thai hatchery stocks of $\mathrm{Cg}$ included in their study.

\section{Effective population size $\left(N_{e}\right)$}

$N_{e}$ directly determines the inbreeding rate of each population (inbreeding coefficient ${ }^{30}, F=1 / 2 N_{e}$ ), thus it is important for sustainability of the populations. Tave ${ }^{31}$ recommended a minimum $N_{e}$ of 4550 individuals for hatchery populations to avoid inbreeding depression. In this study most populations except NY had sufficient $N_{e}$ and hence support the previous conclusion on inbreeding. This may be a result of using large numbers of broodstock, rather than other good broodstock management practices (e.g., mating with a 1:1 sex ratio, and using equal numbers of offspring from each family for broodstock recruitment) ${ }^{30}$, which historically were not routine practices in most hatcheries in Thailand.
The low $N_{e}$ but with comparable level of genetic variation with other populations observed in NY was surprising. However, the explanation was beyond the capacity of our data. Although no evidence of inbreeding was detected in NY based on microsatellite data in this study, low $N_{e}$ of the NY population raises concern of inbreeding depression in the future. Owing to moderate genetic variation of NY, introduction of a new stock may not be a priority. Rather, the broodstock management regime should be improved (e.g., using large numbers of broodstock with 1:1 mating sex ratio, and keeping variance of family size to a minimum when recruiting new generations of brooders).

There might be disagreement regarding the precision of this estimate because the number of microsatellites used was smaller than the 10-20 loci recommended by Luikart et $\mathrm{al}^{32}$, but our sample sizes do fall in the upper range of the recommendation (25-50 individuals). Therefore, we were confident that the precision of the estimates was acceptable.

\section{Genetically distinct hatchery stocks}

Based on the $\mathrm{NJ}$ tree and pairwise $F_{\mathrm{ST}}$, there seemed to be three genetically different stocks of $\mathrm{Cg}$, $\mathrm{SN}+\mathrm{NK}, \mathrm{NR}$, and NY. The AMOVA results confirmed that there were at least two genetic groups existed which comprised northeastern $(\mathrm{SN}+\mathrm{NK}+\mathrm{NR})$ and NY populations. The results also indicated that genetic variation within populations accounted for a major proportion of the overall variation. Highly significant genetic differences among hatcheries in the NE and the NY population reflected limited anthropologic transfer of genetic resources between different regions. A significant variance component among hatcheries within the NE region seems to support this speculation. This information is useful for decision making when distinct gene-pools are selected for further use, e.g., founding a base population for a selection program.

The genetic distances between the aforementioned stocks were similar to those previously reported for four populations from central Thailand $(d=0.036-0.144)^{12}$. This indicated the existence of germplasm diversity of $\mathrm{Cg}$ which is essential for genetic improvement. In fact, $\mathrm{Cg}$ possesses high genetic diversity both in natural habitats and hatcheries in its native countries ${ }^{9,33}$. However, the genetic diversity among populations of the introduced stocks have depended on acquired genetic diversity of the founder stocks as well as gene-flow among them. The Cg stocks in Thailand were from 
at least two geographic origins, Central African Republic and Egypt ${ }^{11}$. They may have been separately managed so that gene-flow was limited, resulting in genetic differentiation among stocks, as previously reported for other stocks from central Thailand ${ }^{12,13}$. On the contrary, the SN and NK stocks were not different, suggesting that they might have originated from the same founder stock(s) and/or there was sufficient gene-flow between them.

\section{Potential uses for genetic improvement}

There have been attempts to improve $\mathrm{Cg}$ strains by crossing different stocks ${ }^{12,34,35}$, but with limited success. To our knowledge, selective breeding which relies mainly on utilization of additive genetic variance has not been used to improve traits in $\mathrm{Cg}$ except for a selection program run by our group ${ }^{36}$. Due to the great potential of selective breeding to improve traits with moderate to high heritability (proportion of additive genetic variance to phenotypic variance) such as growth (e.g., in striped catfish, Pangasianodon hypophthalmus ${ }^{37}$; Asian sea bass, Lates calcarifer ${ }^{38}$ ), selective breeding is recommended for the genetic improvement of $\mathrm{Cg}$ in Thailand. In this regard, the three genetically different Cg stocks, based on pairwise $F_{\mathrm{ST}}$ and the NJ tree, (NR, NY, and NK or SN) are useful as sources of germplasm for the establishment of a founder stock for further selection. The importance of founder stocks with large genetic variation has been highlighted in the successful cases of fish/shellfish genetic improvement, such as Nile tilapia, Oreochromis niloticus $^{39}$, and Pacific white shrimp, Litopenaeus vannamei ${ }^{40}$.

\section{Conclusions and recommendations}

The conclusions and recommendations drawn from this study are as follows. (1) Genetically distinct hatchery stocks of $\mathrm{Cg}$ are available in Thailand. To maximize utilization of these valuable resources, their performance should be studied. (2) Genetic variation within stocks was moderate. However, the stock with low $N_{e}$ should be properly managed by strictly following good broodstock management practices. (3) Based on genetic diversity data, pooling these stocks would expand genetic variation of a novel population. Even though this may not guarantee variation in quantitative traits, this novel population with a large genetic background would be favorable as a founder stock for a selective breeding program.
Acknowledgements: We thank a funding support from Thailand Research Fund under the program Distinguished Research Professor 2016 (Project No. DPG5980003) awarded to U. Na-Nakorn. We appreciate the assistance in sample collection from Dr.Satid Chatchaiphan, Faculty of Fisheries Kasetsart University; Dr.Urai Koolboon, Kalasin University; Mr.Wisanu Srimai and Mr.Wiroon Maneeaphai, Betagro Agro Industry Company Limited. Finally, we thank anonymous referees for their invaluable suggestions that significantly improved the manuscript.

\section{REFERENCES}

1. Na-Nakorn U, Koonawootrittriron S (2015) Challenges for genetic improvement of livestock and aquatic animals. Res \& Knowl 1, 18-25.

2. Dai W, Wang X, Guo Y, Wang Q, Ma J (2011) Growth performance, hematological and biochemical responses of African catfish (Clarias gariepinus) reared at different stocking densities. African J Agri Res 6, 6177-6182.

3. Na-Nakorn U, Brummett RV (2009) Use and exchange of aquatic resources for food and aquaculture: Clarias catfish. Rev Aquacult 1, 214-223.

4. FAO (2018) Fishery and Aquaculture Statistics. Global Aquaculture Production 1950-2016 (FishstatJ). In: FAO Fisheries and Aquaculture Department, Rome. [Available at: http://www.fao.org/ fishery/statistics/software/fishstatj/en]

5. Van Der Bank FH, Grobler JP, Du Preez HH (1992) A comparative biochemical genetic study of three populations of domesticated and wild African catfish (Clarias gariepinus). Comp Biochem Physiol B 101, 387-390.

6. Van Der Walt LD, Van Der Bank FH, Steyn GJ (1993) Allozyme variation in domesticated African catfish (Clarias gariepinus) from The Netherlands. Comp Biochem Physiol B 104, 15-18.

7. Galbusera P (1997) The genetic variability of wild and inbred populations of the African catfish Clarias gariepinus Burchell, 1822. PhD Thesis, Katholieke Universiteit Leuven, Belgium. [Cited after Volckaert FAM, Hellemans B (1999) Survival, growth and selection in a communally reared multifactorial cross of African catfish Clarias gariepinus. Aquaculture 171, 49-64.]

8. Teugels, GG, Guyomard R, Legendre M (1992) Enzymatic variation in African clariid catfishes. J Fish Biol 40, 87-96.

9. Barasa JE, Mdyogolo S, Abila R, Grobler JP, Skilton RA, Bindeman H, Njahira MN, Chemoiwa EJ, et al (2017) Genetic diversity and population structure of the African catfish, Clarias gariepinus (Burchell, 1822) in Kenya: implication for conservation and aquaculture. Belg $J$ Zool 147, 105-127.

10. FishBase (2007) A global information system on fishes. [Available at: www.fishbase.org/home.htm] 
11. Li Y, Helleman B, Pouyaud L, Volkaert FAM (2000) Origin and genetic diversity of aquacultured catfish (Clarias gariepinus) in SE Asia. In: Catfish Asia Workshop, Bogor, Indonesia.

12. Wachirachaikarn A, Rungsin W, Srisapoome P, NaNakorn U (2009) Crossing of African catfish (Clarias gariepinus) strains based on strain selection using genetic diversity data. Aquaculture 290, 53-60.

13. Koolboon U, Koonawootrittriron S, Kamolrat W, NaNakorn U (2014) Effects of parental strains and heterosis of the hybrid between Clarias macrocephalus and Clarias gariepinus. Aquaculture 424425, 131-139.

14. Taggart JB, Hynes RA, Prodöhl PA, Ferguson A (1992) A simplified protocol for routine total DNA isolation from salmonid fishes. $J$ Fish Biol 40, 963-965.

15. Galbusera P, Volckaert FA, Hellemans B, Ollevier F (1996) Isolation and characterization of microsatellite markers in the African catfish Clarias gariepinus (Burchell, 1822). Mol Ecol 5, 703-705.

16. Guo SW, Thompson EA (1992) Performing the exact test of Hardy-Weinberg proportion for multiple alleles. Biometrics 48, 361-372.

17. Raymond M, Rousset F (1995) GENEPOP (Version 1.2 ), population genetics software for exact tests and ecumenicism. J Hered 86, 248-249.

18. Hochberg Y (1988) A sharper Bonferroni procedure for multiple tests of significance. Biometrika 75, 800-802.

19. Rice WR (1989) Analyzing table of statistical tests. Evolution 43, 223-225.

20. Oosterhout CV, Hutchinson WF, Wills DPM, Shipley P (2004) MICRO-CHECKER: software for identifying and correcting genotyping errors in microsatellite data. Mol Ecol Notes 4, 535-538.

21. Do C, Waples RS, Peel D, Macbeth, GM, Tillet BJ, Ovenden JR (2014) NeEstimator V2: reimplementation of software for the estimation of contemporary effective population size $\left(N_{e}\right)$ from genetic data. Mol Ecol Resour 14, 219-214.

22. Goudet J (2001) FSTAT, a program to estimate and test gene diversities and fixation indices. [Available at www2.unil.ch/popgen/softwares/fstat.htm]

23. Excoffier LG, Schneider S (2006) Arlequin (version 3.0): an integrated software package for population genetics data analysis. Evolut Bioinform 1, 47-50.

24. Felsenstein J (1993) PHYLIP (Phylogeny Inference Package) version 3.5c. Department of Genetics, University of Washington, Seattle.

25. Cavalli-Sforza LL, Edwards AWF (1967) Phylogenetic analysis: models and estimation procedures. Evolution 21, 550-570.

26. Allendorf FW, Phelps SR (1980) Loss of genetic variation in a hatchery stock of cutthroat trout. T Am Fish Soc 109, 537-543.
27. Frankham R, Gilligan DM, Morris DR, Briscoe DA (2001) Inbreeding and extinction: effects of purging. Conserv Genet 2, 279-284.

28. De Woody JA, Avise JC (2000) Microsatellite variation in marine, freshwater and anadromous fishes compared with other animals. J Fish Biol 56, 461-473.

29. Hedrick PW (1985) Genetics of Populations, Jones and Bartlett Publishers, Inc., Boston.

30. Falconer DS, Mackay TFC (1996) Introduction to Quantitative Genetics, 4th edn, Longman, Essex.

31. Tave D (1993) Genetics for Hatchery Managers, 2nd edn, Kluwer Academic Publisher, Boston.

32. Luikart G, Ryman N, Tallmon DA, Schwartz MK, Allendorf FW (2010) Estimation of census and effective population sizes: the increasing usefulness of DNAbased approaches. Conserv Genet 11, 355-373.

33. Barasa JE, Abila R, Grobler JP, Agaba M, Chemoiwa EJ, Kaunda-Arara B (2016) High genetic diversity and population differentiation in Clarias gariepinus of Yala Swamp: evidence from mitochondrial DNA sequences. J Fish Biol 89, 2557-2570.

34. Volckaert FAM, Hellemans B (1999) Survival, growth and selection in a communally reared multifactorial cross of African catfish (Clarias gariepinus). Aquaculture 171, 49-64.

35. Sunarma A, Carman O, Zairin Jr M, Alimuddin A (2016) Interpopulation crossbreeding of farmed and wild African catfish Clarias gariepinus (Burchell 1822) in Indonesia at the nursing stage. Aquat Living Resour 29, ID 303, 1-8.

36. Srimai W, Koonawootrittriron S, Manee-aphai W, Chatchaiphan S, Koolboon U, Na-Nakorn U (2019) Genetic parameters and genotype-environment interaction for growth traits of North African catfish, Clarias gariepinus (Burchell, 1822). Aquaculture 501, 104-110.

37. Sang NV, Klemetsdal G, Ødegård J, Gjøen HM (2012) Genetic parameters of economically important traits recorded at a given age in striped catfish (Pangasianodon hypophthalmus). Aquaculture 344-349, 82-89.

38. Domingos J, Smith-Keune C, Robinson N, Loughnan S, Harrison P, Jerry D (2013) Heritability of harvest growth traits and genotype-environment interactions in barramundi, Lates calcarifer (Bloch). Aquaculture 402-403, 66-75.

39. Bentsen HB, Eknath AE, Palada-de Vera MS, Danting JC, Bolivar HL, Reyes RA, Dionisio EE, Longalong FM, et al (1998) Genetic improvement of farmed tilapia: growth performance in a complete diallel cross experiment with eight strains of Oreochromis niloticus. Aquaculture 160, 145-173.

40. Argue BJ, Arce SM, Lotz AM, Moss SM (2002) Selective breeding of Pacific white shrimp (Litopenaeus vannamei) for growth and resistance to Taura Syndrome virus. Aquaculture 204, 447-460. 